\title{
Prion disease modelled in Drosophila
}

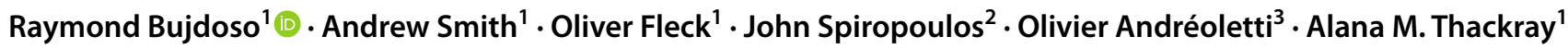

Received: 27 August 2021 / Accepted: 17 January 2022 / Published online: 29 January 2022

(c) The Author(s) 2022

\begin{abstract}
Prion diseases are fatal neurodegenerative conditions of humans and various vertebrate species that are transmissible between individuals of the same or different species. A novel infectious moiety referred to as a prion is considered responsible for transmission of these conditions. Prion replication is believed to be the cause of the neurotoxicity that arises during prion disease pathogenesis. The prion hypothesis predicts that the transmissible prion agent consists of $\operatorname{PrP}^{\mathrm{Sc}}$, which is comprised of aggregated misfolded conformers of the normal host protein $\mathrm{PrP}^{\mathrm{C}}$. It is important to understand the biology of transmissible prions and to identify genetic modifiers of prion-induced neurotoxicity. This information will underpin the development of therapeutic and control strategies for human and animal prion diseases. The most reliable method to detect prion infectivity is by in vivo transmission in a suitable experimental host, which to date have been mammalian species. Current prion bioassays are slow, cumbersome and relatively insensitive to low titres of prion infectivity, and do not lend themselves to rapid genetic analysis of prion disease. Here, we provide an overview of our novel studies that have led to the establishment of Drosophila melanogaster, a genetically well-defined invertebrate host, as a sensitive, versatile and economically viable animal model for the detection of mammalian prion infectivity and genetic modifiers of prion-induced toxicity.
\end{abstract}

Keywords Drosophila $\cdot$ Infectivity $\cdot$ Neurodegeneration $\cdot$ Prion $\cdot$ Transmissible

\section{Introduction}

Prion diseases are fatal and transmissible neurodegenerative diseases of the CNS, which include Creutzfeldt-Jakob disease (CJD) of humans, bovine spongiform encephalopathy (BSE) in cattle, chronic wasting disease (CWD) of cervids and scrapie in sheep (Prusiner 2004). A central feature of prion disease pathogenesis is the accumulation of $\operatorname{PrP}^{\mathbf{S c}}$, an abnormal conformer of the host protein $\operatorname{PrP}^{\mathbf{C}}$, in the brains of affected individuals (Bolton et al. 1982).

Raymond Bujdoso

rb202@cam.ac.uk

Alana M. Thackray amt27@cam.ac.uk

1 Department of Veterinary Medicine, University of Cambridge, Madingley Road, Cambridge CB3 OES, UK

2 Pathology Department, Animal and Plant Health Agency (APHA), Weybridge, Woodham Lane, New Haw, Surrey KT15 3NB Addlestone, UK

3 UMR INRA ENVT 1225-Hôtes-Agents Pathogènes, Ecole Nationale Vétérinaire de Toulouse, 23 Chemin des Capelles, 31076 Toulouse, France
The prion hypothesis proposes that a novel proteinaceous moiety termed a prion is responsible for transmission of these diseases (Prusiner 1982). Significant evidence suggests that prions comprise principally, if not solely, of $\mathrm{PrP}^{\mathrm{Sc}}$ since prions that are transmissible in vivo can be generated from recombinant PrP in vitro (Legname et al. 2004; Wang et al. 2010).

Prions lack a nucleic acid-based genome and do not stimulate a typical immune response in those hosts infected with these novel transmissible agents (Prusiner 2004). Consequently, prions are not detected by commonly used techniques that identify conventional pathogens, such as viruses and bacteria. Instead, in vitro techniques can be used to identify the surrogate marker of transmissible prions, namely $\mathrm{PrP}^{\mathrm{Sc}}$. Western blot can be used to detect proteinase K (PK)resistant $\operatorname{PrP}^{\mathbf{S c}}$ (Schaller et al. 1999) while immunoassays can be used to detect both PK-resistant and PK-sensitive $\operatorname{PrP}^{\mathrm{Sc}}$ (Safar et al. 1998; Thackray et al. 2007). In addition, in vitro amplification of $\operatorname{PrP}^{\mathrm{Sc}}$, mediated by prion-seeding activity, can be achieved by protein misfolding cyclic amplification (PMCA) and RT-QuIC (Saborio et al. 2001; Wilham et al. 2010). These biochemical-based procedures are used on the premise that the amount of $\mathrm{PrP}^{\mathrm{Sc}}$ correlates with the 
degree of prion infectivity (Beekes et al. 1996; Bolton et al. 1991; Jendroska et al. 1991). However, the level of $\operatorname{PrP}^{\text {Sc }}$ and prion infectivity are not always congruent (Lasmezas et al. 1997; Miyazawa et al. 2011), and as a consequence, in vivo bioassay in a suitable experimental host remains the most reliable method for the detection of bona fide prion infectivity.

Prion bioassays have been used to measure the amount of prion infectivity in different tissues and fluids derived from prion-infected individuals. The goal of these studies is to understand the biology of infectious prions and to ensure the safety of animal products destined for human consumption, since animal prion diseases are a significant public health risk through their potential for zoonotic transmission. This risk has been realised with the identification of variant CJD (vCJD) in humans as a consequence of the consumption of prion-contaminated bovine products. The discovery of new prion diseases, such as atypical scrapie in sheep (Benestad et al. 2003), atypical BSE in cattle (Beringue et al. 2006; Biacabe et al. 2004) and camelid prion disease (Babelhadj et al. 2018), and the emergence of new reservoirs of CWD in Europe (Benestad et al. 2016) present unidentified zoonotic risks to human health. In addition to their role in public health, prion transmission studies are used to probe the molecular basis of prion propagation and the transmission barrier that controls their passage between species (Prusiner 2004), and to help provide an understanding of the cellular and molecular mechanisms of prion-induced neurotoxicity.

Prion diseases are difficult to study under natural conditions as the exact time of prion exposure cannot be determined and the full course of the disease cannot be analysed. As a consequence, prion diseases are modelled in experimental animal hosts. To date, a variety of different mammalian species, ranging from large experimental animals, including non-human primates, to small rodents, have been used as hosts in prion transmission studies (Brandner and Jaunmuktane 2017). However, prion studies that rely on mammalian species as the experimental host have practical disadvantages since they take a considerably long time, are expensive, do not readily detect low levels of prion infectivity and are subject to increasing ethical debate. Here, we describe our studies that have established Drosophila melanogaster as a more sensitive, economically viable host for the relatively rapid detection of mammalian prions and one that lends itself to the search for genetic modifiers of prioninduced neurotoxicity.

\section{Mammalian species as hosts in prion transmission studies}

Developments in prion biology have been inextricably linked to involvement of a wide range of animal species used to detect prion infectivity, including large mammals (Brandner and Jaunmuktane 2017). The first reported transmission of a prion disease was by Cullié and Chelle in 1936 who inoculated brain and spinal cord from a scrapie-affected sheep into healthy same-species recipients by various routes including intraocular administration (Cullié and Chelle 1936). Early attempts to identify the molecular nature of the transmissible agent were performed using fractionated scrapie-infected ovine brains and bioassays in sheep (Gordon 1946; Pattison and Millson 1960; Stamp et al. 1959). BSE-infected blood transfusion experiments have been performed in sheep in order to model blood-borne vCJD transmission in humans (Hunter 2003; Salamat et al. 2021). A variety of non-human primates, including chimpanzees, have been inoculated with brain material from human prion disease in order to establish these conditions were transmissible (Gajdusek et al. 1966). Cynomolgus macaques inoculated with brain extracts from classical BSE-infected cattle produced a pathological phenotype that was almost identical to vCJD, which provided evidence to establish this bovine prion disease as a zoonotic (Lasmezas et al. 1996). Old World and New World monkeys have collectively been used to investigate the zoonotic potential of other animal prion diseases including scrapie (Comoy et al. 2015; Gibbs et al. 1980; Gibbs and Gajdusek 1972), atypical BSE (Comoy et al. 2008) and CWD (Marsh et al. 2005; Race et al. 2018). In addition to these prion transmission studies, experimental pathogenesis studies of scrapie, BSE and CWD have been performed in sheep, cattle and cervids, respectively (Orge et al. 2021).

Small rodents including mice, hamsters and bank voles have been used extensively as experimental models of prion disease (Groschup and Buschmann 2008). Chandler was the first to transmit mammalian prions to rodents through the successful inoculation of scrapie-infected goat brain material into wild-type mice (Chandler 1961). Serial transmission of sheep scrapie through inbred mouse lines allowed adaptation and characterisation of different prion strains (Chandler 1961; Fraser and Dickinson 1968). Hamsters were used as the experimental bioassay host in landmark experiments that identified $\mathrm{PrP}^{\mathrm{Sc}}$ as the biochemical component that co-purified with prion infectivity following fractionation of scrapie-infected hamster brains (McKinley et al. 1983). Bank voles have been identified as a host permissive for facilitated transmission of prions from multiple different species (Cartoni et al. 2005; Nonno et al. 2006).

Inoculation of wild-type mice and hamsters with different species' forms of prions helped establish the phenomenon of the transmission barrier whereby successful passage between species is generally less efficient compared to propagation within their natural hosts (Pattison 1965). Inefficient attack rates and prolonged incubation times at primary passage are indicative of a prion transmission barrier, whereas enhanced attack rates and shortened incubation times are observed following serial passage in hosts 
that express the same $\operatorname{PrP}^{\mathbf{C}}$ amino acid sequence (Hill et al. 2000). Abrogation of the species barrier has been achieved in mice with the endogenous murine PrP gene inactivated and that overexpress a PrP transgene homologous to the host from which the prion isolates were derived (Brandner and Jaunmuktane 2017; Moreno and Telling 2017). This has led to a plethora of different mouse models that allow facilitated transmission of prions, including those of sheep, bovine, human and cervid origin, in mice transgenic for PrP genes from these different species.

Despite their considerable importance, prion transmission studies in mammalian species are problematic. Those using large experimental animals are hampered by long incubation times prior to the onset of clinical prion disease and significant practical difficulties and large financial costs associated with housing these species. Collectively, these issues result in constraints on the number of large animals used in each experiment with subsequent loss of statistical power. While small rodents are less cumbersome to maintain and generally show shorter incubation times than large experimental animals, prion transmissions in PrP transgenic mice may take many months or even years to complete and show only a $1-2 \log \mathrm{LD}_{\mathbf{5 0}}$ higher infectivity titre than the respective homologous species (Groschup and Buschmann 2008). In addition, there is increasing ethical debate about the use of mammalian hosts to bioassay prions, in particular non-human primates. For these reasons, it is important to develop more efficient bioassays to assess mammalian prion infectivity, preferably using a less sentient host.

\section{Drosophila melanogaster as a versatile experimental animal system}

New animal models of mammalian prion diseases should allow sensitive and relatively rapid detection of prion infectivity, ideally in a genetically well-defined animal system that enables analysis of genes and metabolic pathways involved in prion neurotoxicity. The successful application of PrP transgenesis in rendering xenogeneic hosts susceptible to different species forms of prions (Crozet et al. 2001; Vilotte et al. 2001) provides an opportunity to explore the development of non-mammalian animal models of prion disease in pursuit of these goals.

Drosophila melanogaster has emerged as a model system for the study of complex biological processes, such as mammalian neurodegenerative disease (Lu and Vogel 2009). This arises for several reasons: (i) the brains of Drosophila and mammalian species are composed of similar components (i.e. neurons and neuronal circuitry), and the nature of ion channels, neurotransmitters and synaptic proteins are highly conserved between mammals and the fly (Lessing and Bonini 2009); (ii) Drosophila is a genetically well-defined organism that lends itself to the production of transgenic flies that express proteins in a tissue-specific distribution; (iii) the normal physiology and development of Drosophila is well characterised so that phenotypic assays can readily detect neurotoxicity in the live organism (Marsh and Thompson 2006); and (iv) large numbers of flies can be produced in a short time, which correlated with their relatively short life span (Piper et al. 2005), allows rapid, statistically robust data collection.

Drosophila have already proved to be an important animal model to analyse the genetics of mammalian neurodegeneration. For example, the Drosophila gene amyloid precursor protein-like (Appl) gene encodes a protein product (APPL) (Rosen et al. 1989) that is orthologous to the human amyloid beta precursor protein (APP) associated with Alzheimer's disease (Kang et al. 1987). Deletion of Appl in Drosophila causes behavioural defects that can be compensated for by transgenic expression of the human gene APP (Luo et al. 1992). In addition, mutagenesis screens in Drosophila have led to the isolation of flies that show late-onset progressive degeneration of the adult nervous system that resembles human diseases (Min and Benzer 1999). Significantly, Drosophila have been used to model a number of human neurodegenerative diseases including Parkinson's disease (Auluck et al. 2002; Feany and Bender 2000) and tauopathies (Fulga et al. 2007; Wittmann et al. 2001) such as Alzheimer's disease (Greeve et al. 2004; Iijima et al. 2004). For these reasons, we considered that Drosophila melanogaster could be an ideal animal system for development as an invertebrate model of mammalian prion disease. Some general aspects of Drosophila husbandry are highlighted in Fig. 1.

\section{Drosophila efficiently express mammalian PrP}

Drosophila melanogaster and other members of the arthropod phylum do not show the presence of an orthologous PrP gene in their genome and therefore do not normally express $\operatorname{PrP}^{\mathbf{C}}$ (Rivera-Milla et al. 2006). Only hosts that express $\operatorname{PrP}^{\mathbf{C}}$ are susceptible to prion-induced toxicity, and formation of the toxic moiety occurs concomitantly with prion replication (Bueler et al. 1993; Mallucci et al. 2003). Consequently, it is necessary for Drosophila to be rendered transgenic for PrP expression in order to be permissive for mammalian prion propagation.

Several groups have shown the expression of mammalian PrP in Drosophila. The first report of PrP transgenic Drosophila was by Raeber et al. who expressed wild-type hamster prion protein under the control of the fly hsp70 gene promoter (Raeber et al. 1995). Hamster PrP expressed in Drosophila exhibited variable glycosylation and the presence of a glycosylphosphatidyl inositol (GPI) anchor, features reminiscent of those seen in the native host. PrP expressed in Drosophila showed a lower molecular mass compared to expression in mammalian species. This arises because in 
Fig. 1 Some general aspects of Drosophila husbandry. (a) Phenotypic sorting of Drosophila, or 'fly pushing', requires the use of a stereomicroscope; (b) Drosophila are anesthetised using $\mathrm{CO}_{2}$ prior to sorting; (c) Drosophila are housed in vials and raised on cornmeal media; and (d) prion-inoculated Drosophila are maintained at $25^{\circ} \mathrm{C}$ in incubators
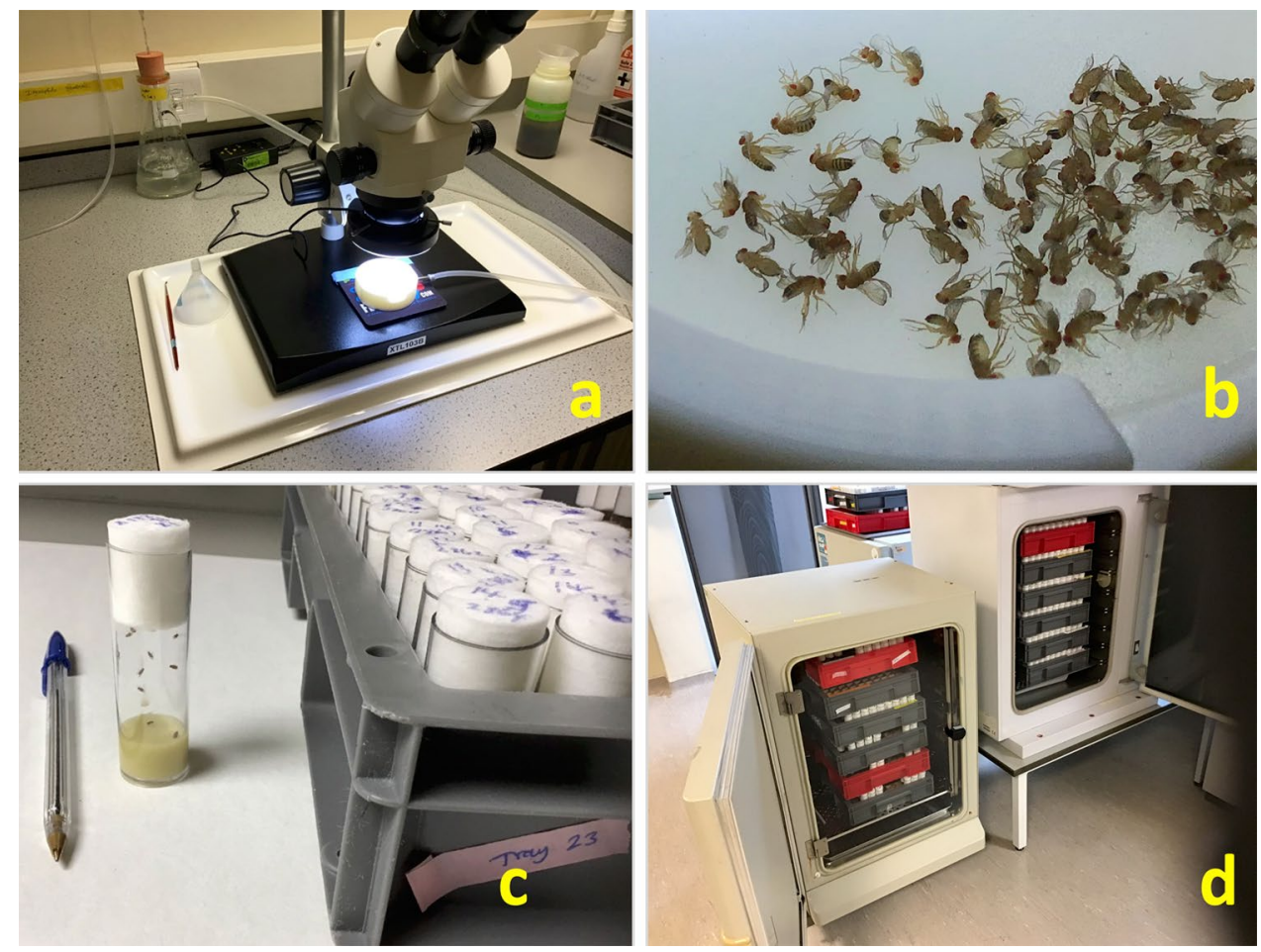

Drosophila, post synthetic trimming reactions of $N$-linked glycosylation moieties result in a lack of sialylation in contrast to the complex sugar groups that are added to proteins in mammalian systems (Marchal et al. 2001; März et al. 1995; Repnikova et al. 2010). Subsequent studies by others showed that Drosophila transgenic for wild-type hamster or mouse PrP was characterised by locomotor dysfunction, as well as degeneration and vacuolation in the fly brain (FernandezFunez et al. 2009, 2010). Locomotor dysfunction in murine PrP transgenic Drosophila was mitigated by mutations in the $\alpha$-helix 1- $\beta$-strand 2 loop (Sanchez-Garcia et al. 2016) and in $\alpha$-helix 3 (Sanchez-Garcia et al. 2013). Expression of Val129 human PrP in Drosophila was reported to induce a toxic eye phenotype that was exacerbated when PERK, a component of the unfolded protein response, was overexpressed at the same time (Fernandez-Funez et al. 2017). However, Park et al. determined that the unfolded protein response did not appear to be activated in Drosophila transgenic for murine PrP (Park et al. 2011).

Several groups have reported the generation of Drosophila transgenic for expression of mammalian PrP harbouring mutations associated with genetic prion disease. Deleault et al. expressed mouse PrP in the fly that contained additional $\mathrm{N}$-terminal octapeptide repeat inserts, a mutation associated with familial CJD, which did not induce a toxic fly phenotype (Deleault et al. 2003). Drosophila transgenic for mouse PrP containing the P101L mutation, which is associated with GSS in humans, developed a toxic phenotype, that included larval lethality and locomotor dysfunction and reduced survival in adult flies, that was not seen in Drosophila that expressed wild-type mouse PrP (Gavin et al. 2006). However, expression of the P101L PrP in Drosophila neurons was subsequently determined to be more than 20 times greater than that of wild-type PrP (Gavin et al. 2008). Analysis of further Drosophila fly lines with expression of P101L mouse PrP showed that the action potential frequency of neurons, as well as fly locomotor ability and survival, was reduced in mutant mouse PrP transgenic Drosophila relative to flies that expressed wild-type mouse PrP (Choi et al. 2010; Gavin et al. 2006; Murali et al. 2014). Meanwhile, Robinson et al. showed that flies which expressed 3F4 epitope wild-type mouse PrP had synaptic changes, including increases of miniature excitatory junctional currents, synaptic vesicle sizes and vesicle release probability (Robinson et al. 2014). However, these changes were less pronounced in flies that expressed P101L mouse PrP, which suggested that the mutated PrP was less functional at synapses compared to wild-type PrP.

While the aforementioned studies of PrP transgenic Drosophila have been informative, they also have their shortcomings. In the majority of cases, the PrP transgenic Drosophila described above were generated by random incorporation of the transgene into the fly genome. This has the potential for mutational positional effects on either PrP expression or endogenous gene expression, or multiple transgene copy number, thereby complicating comparisons between different fly lines. Some of the studies reported spontaneous toxic phenotypes in Drosophila that expressed either wild-type or 
mutated forms of PrP. However, none of these studies examined if this was a transmissible toxicity, either by fly-to-fly or fly-to-mammalian host transmission, in order to demonstrate that the effect was prion-mediated. In addition, some of the studies, including those that investigated wild-type $\operatorname{PrP}$ expression in Drosophila, reported reactivity of transgenic fly material with monoclonal antibody $15 \mathrm{~B} 3$, a putative disease-associated PrP-specific reagent. However, these 15B3 observations were not supported with either the biochemical detection of proteinase K-resistant PrP by SDS PAGE/ western blot or detection of PMCA prion-seeding activity, which are both well-established methods for the detection of $\mathrm{PrP}^{\mathrm{Sc}}$, the surrogate marker of transmissible prions. Therefore, it is reasonable to conclude that these early studies clearly showed that mammalian PrP could be expressed in Drosophila, none of the studies addressed whether any of the observed phenotypic or biochemical responses were due to effects of bona fide transmissible prions.

\section{Prion disease modelled in Drosophila}

We modelled classical scrapie of sheep in the fly in order to test the hypothesis that PrP transgenic Drosophila are susceptible to prion-induced toxicity and permissive for mammalian prion propagation. Classical scrapie, the prototypic prion disease, is a naturally occurring acquired condition of sheep and other small ruminants that exhibits strain diversity (Hunter 1997). Sheep that express the ovine PrP variant $\mathrm{V}^{136} \mathrm{R}^{154} \mathrm{Q}^{171}$ (termed VRQ, where $\mathrm{V}$, $\mathrm{R}$ and $\mathrm{Q}$ stand for valine, arginine and glutamine, respectively) or $\mathrm{A}^{136} \mathrm{R}^{154} \mathrm{Q}^{171}$ (termed ARQ, where A stands for alanine) are susceptible to classical scrapie (Clouscard et al. 1995; Goldmann et al. 1994). Furthermore, facilitated transmission of classical scrapie occurs in hosts rendered transgenic for these ovine PrP variants (Crozet et al. 2001; Thackray et al. 2008; Vilotte et al. 2001). In this context, we tested the hypothesis that Drosophila transgenic for VRQ or ARQ ovine PrP would be susceptible to classical scrapie infection.

We generated Drosophila transgenic for VRQ and ARQ ovine PrP through the site-specific pUASTattB/ PhiC31 integrase system, which delivers a single copy of the transgene of interest into a defined landing pad in the fly genome (Bischof et al. 2007) as outlined in Fig. 2. The PrP transgenes comprised DNA encoding mature length ovine PrP (amino acid residues 25-232) flanked by the coding sequences for an insect leader sequence peptide (Green et al. 2000) at the $5^{\prime}$ end and the ovine GPI anchor sequence at the $3^{\prime}$ end. The PrP constructs were ligated into the Drosophila integration vector pUASTattB for injection into embryos of the 51D fly line. Stable balanced UAS-ovine PrP transgenic Drosophila were generated by conventional fly crossing and crossed with the elav-GAL4 driver fly line to stimulate pan neuronal PrP expression.
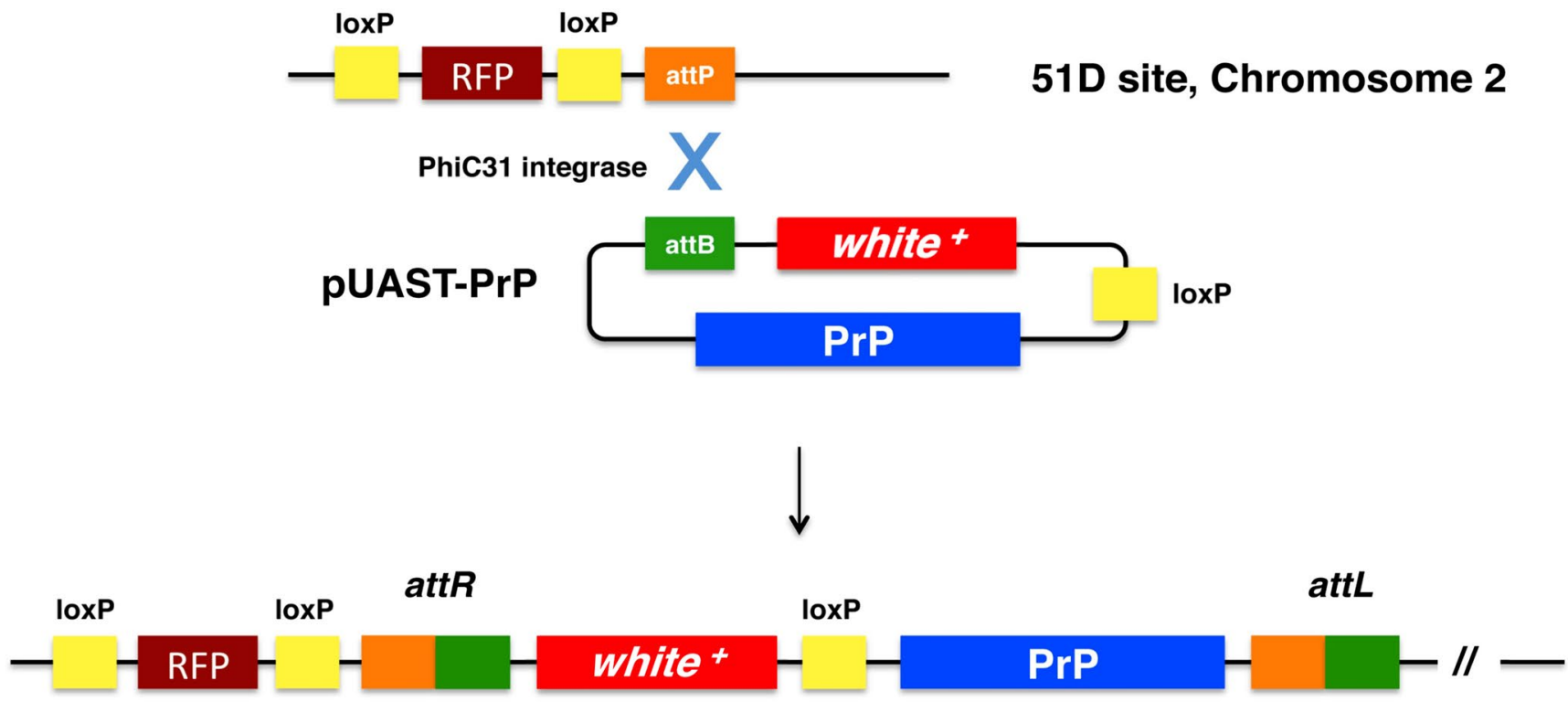

Fig. 2 PhiC31/pUAST-mediated site-specific transgenesis in Drosophila. The pUASTattB-PrP plasmid contains an attB fragment, the white $^{+}$marker gene and the PrP transgene. During pUAST/PhiC31 integrase-mediated integration, the unique attP site in the $\mathrm{ZH}$-attP$51 D$ fly line genome recombines with the pUAST attB site in the pUAST-PrP vector forming attR and attL sites in the generated trans- genic flies (Bischof et al. 2007). This results in the integration of pUASTattB-PrP DNA into the fly genome, thereby creating attR and att $L$ hybrid sites. The loxP sites allow the elimination of the red fluorescence protein (RFP) and white ${ }^{+}$marker genes after PhiC31mediated transgenesis. (Taken from Thackray et al., Biochem. $J .$, 2014a, 463: pp31-40, supplementary data) 
Western blot analysis showed that ovine PrP expressed in Drosophila had a molecular mass of 29-31 kDa and comprised at least two major protein bands, and a third less intense band, similar to that of other species forms of PrP expressed in Drosophila (Thackray et al. 2012b). Prion protein expression was also evident associated with neuronal cell bodies of the ovine PrP fly lines as shown in Fig. 3. Adult fly brains exhibited occasional vacuolar lesions of variable size that were distributed randomly throughout ovine PrP Drosophila and control 51D flies that lack PrP expression. This indicated that the detected vacuoles were artefactual and that overexpression of mammalian PrP in Drosophila alone does not adversely affect neuronal integrity or mediate neurodegeneration.

We next exposed Drosophila, with pan neuronal ovine PrP expression, to exogenous prions in order to determine whether these flies were susceptible to prion-induced neurotoxicity. To do so, fly food was supplemented with scrapieinfected sheep brain homogenate to allow oral exposure of VRQ ovine PrP Drosophila larvae to ovine prions (Thackray
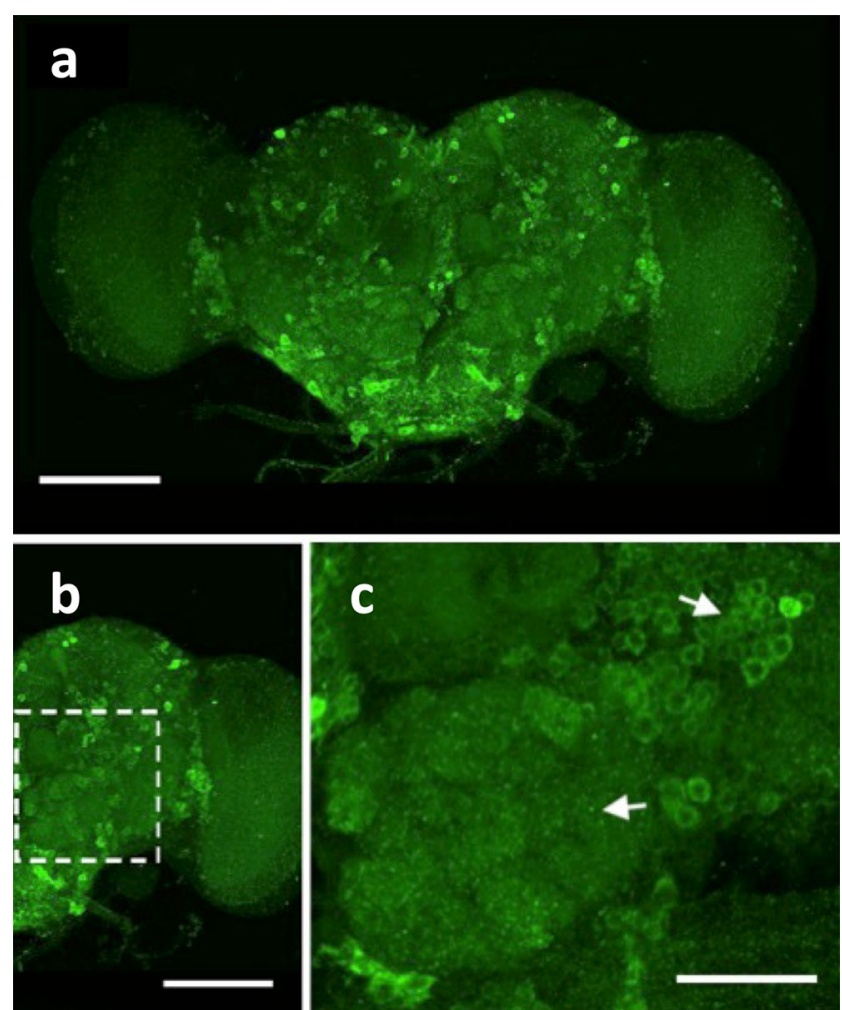

Fig. 3 Distribution of prion protein in the brain of ovine PrP transgenic Drosophila. Adult (5-day-old) Elav > ARQ ovine PrP Drosophila fly brains were isolated and stained with anti-PrP monoclonal antibody $6 \mathrm{H} 4$ detected by Alexa Fluor 488-labelled goat anti-mouse IgG. (a) Whole brain, (b) section of whole brain with an enlargement of the dashed area in (c) that shows PrP expression associated with neuronal cell bodies (upper arrow) and antennal lobe glomeruli (lower arrow). Scale bars $100 \mathrm{~nm}$ in (a) and (b) and $40 \mathrm{~nm}$ in (c). (Modified from Thackray et al., Biochem. J., 2012b, 444: pp487-495) et al. 2012a), which mimicked what is considered to be the natural route of prion infection in most cases of transmissible mammalian prion disease (Glatzel and Aguzzi 2000; Mabbott and MacPherson 2006), including classical scrapie of sheep (van Keulen et al. 2008). Remarkably, after hatching, prion-exposed adult PrP Drosophila showed an accelerated decline in locomotor ability that became progressively more severe with age and displayed a shortened survival time compared to similar flies fed control prion-free sheep brain material (Thackray et al. 2014a, b, 2012a). These neurotoxic phenotypes were PrP-dependent and prion-specific since they were only induced in PrP transgenic Drosophila and only after exposure to scrapie inoculum.

\section{Mammalian prions replicate in Drosophila}

In mammalian species, clinical signs in prion affected individuals arise through neurodegenerative processes initiated by the conversion of $\operatorname{PrP}^{\mathbf{C}}$ to $\operatorname{PrP}^{\mathrm{Sc}}$. Accordingly, we considered that the neurotoxic phenotype observed in scrapieexposed ovine PrP Drosophila was due to prion replication in the fly. To verify if this was the case, we examined scrapie-exposed Drosophila for the presence of hallmark features of mammalian prion disease, namely, accumulation of prion-seeding activity, PK-resistant $\mathrm{PrP}^{\mathrm{Sc}}$ and transmissible prions (Oesch et al. 1985; Prusiner 2004).

To assess accumulation of prion-seeding activity, Drosophila were exposed at the larval stage to either scrapieinfected or control prion-free sheep brain material. At various time points ( $\leq 40$ days) during their adult lifespan, head homogenate was prepared from groups of flies for use as substrate in PMCA reactions. Prion-seeding activity was only observed in head homogenate prepared from scrapieinfected VRQ PrP Drosophila aged $\geq 20$ days of age and showed a progressive increase in titre from 20 to 40 days of age (Thackray et al. 2018). In contrast, no prion-seeding activity was detected in PMCA reactions with seed prepared from VRQ PrP Drosophila mock infected with control prion-free sheep brain material, or from scrapie-exposed or mock-infected 51D control flies.

The prion-seeding activity observed in scrapie-inoculated VRQ PrP Drosophila was associated with the presence of PK-resistant PrP, a pathognomonic marker of prion disease in mammalian hosts (Prusiner 2004). SDS PAGE/western blot detection of PK-resistant PrP in VRQ PrP Drosophila showed that this material had a different molecular mass profile to that present in the original PG127 inoculum, which was expected considering the differences in $N$-linked glycosylation that exists between Drosophila and mammalian hosts (Marchal et al. 2001; März et al. 1995; Repnikova et al. 2010).

We performed fly-to-mouse transmission experiments in order to detect bona fide prion infectivity accumulation in 
scrapie-exposed ovine PrP Drosophila. In these experiments, aliquots of the same head homogenate prepared from flies used as seed in the PMCA experiment described above was inoculated into the $\operatorname{tg} 338$ mouse line, which is transgenic for VRQ ovine PrP. No prion infectivity was detected in head homogenates prepared from 5 or 10-day-old PG127exposed VRQ PrP Drosophila, while that from 20-day-old flies gave an incomplete attack rate in tg338 mice. In contrast, $\operatorname{tg} 338$ mice inoculated with head homogenates prepared from 30 and 40-day-old scrapie-exposed VRQ PrP Drosophila developed a $100 \%$ attack rate for clinical prion disease transmission, with incubation times of $89 \pm 3$ and $89 \pm 2$ days, respectively. Prion disease in mice that showed clinical signs of the condition was confirmed by western blot detection of PK-resistant PrP27-30 as shown by the data in Fig. 4. Furthermore, PET blot analysis of the brains of clinically affected mice showed the typical distribution of $\mathrm{PrP}^{\mathrm{Sc}}$ in PG127 scrapie-inoculated tg338 mice. No evidence of clinical prion disease or abnormal PrP accumulation was observed in mice inoculated with head homogenates prepared from VRQ PrP Drosophila exposed to control sheep brain homogenate or from 51D flies inoculated with scrapie-infected or control sheep brain material. This result excludes the suggestion that carry-over of the original sheep inoculum was an explanation for prion infectivity detection in scrapie-exposed VRQ ovine PrP Drosophila. The fly-tomouse transmission experiment was repeated twice using fly head homogenates obtained in two independent experiments (using the same fly lines and the same sheep scrapie prion strain). The incubation times and attack rates we observed were consistent across the three independent experiments (Thackray et al. 2018).
Fig. 4 Detection of prion infectivity in scrapie-exposed PrP transgenic Drosophila. Elav $\times$ VRQ PrP transgenic (VRQ) and Elav $\times 51 \mathrm{D}$ (51D) Drosophila were exposed at the larval stage to PG127 scrapieinfected or prion-free control sheep brain material. At various times after hatching, head homogenate was prepared from harvested flies and inoculated into tg338 mice. Inoculated mice were euthanised when they showed clinical signs of prion infection or after 250 days for those that did not develop clinical disease. Mice were considered positive for prion disease when PK-resistant PrP27-30 was detected in brain tissue by western blot. (a) Western blot detection of PK-resistant PrP27-30 in the brains of $\operatorname{tg} 338$ mice with clinical prion disease. Western blot (WB) control is PG127 sheep scrapie material. Molecular mass markers in $\mathrm{kDa}$ shown on the right; $(\mathbf{b}-\mathbf{e})$ PET blot analysis of $\operatorname{tg} 338$ mouse brains from animals inoculated with 40-day-old Elav $\times 51 \mathrm{D}$ (51D) $(\mathbf{b}, \mathbf{d})$ or Elav $\times$ VRQ PrP transgenic (VRQ) (c, e) Drosophila exposed to prionfree control $(\mathbf{b}, \mathbf{c})$ or PG127 scrapie-infected $(\mathbf{d}, \mathbf{e})$ sheep brain material. Scale bar represents $150 \mu \mathrm{m}$. (Modified from Thackray et al., Brain, 2018, 141: pp2700-2710) a

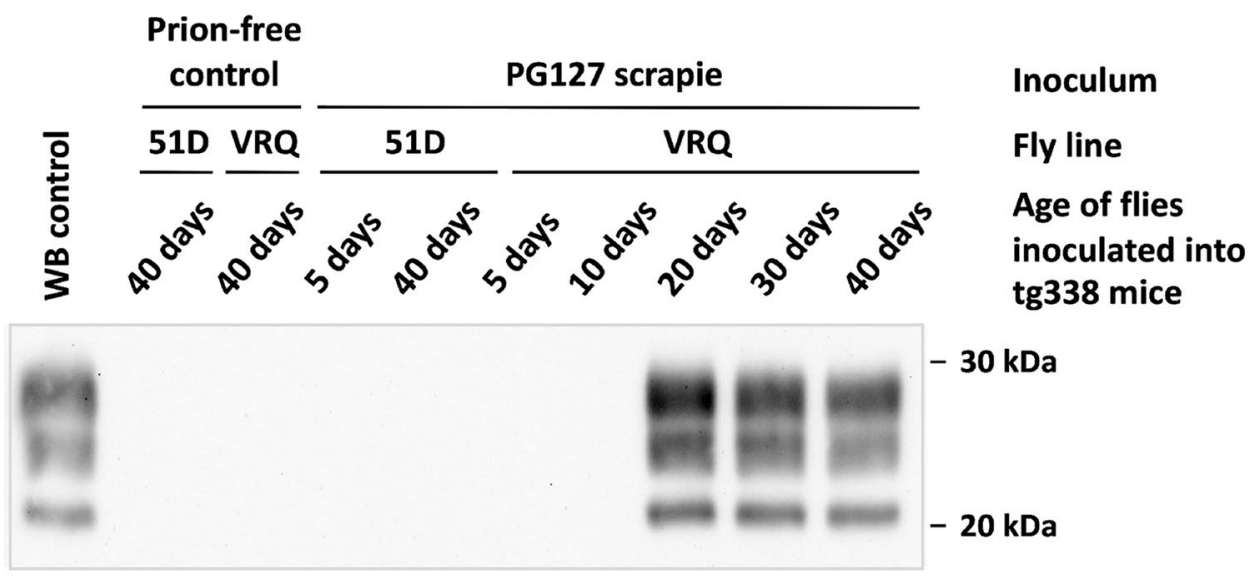

Fly line inoculated into tg338 mice

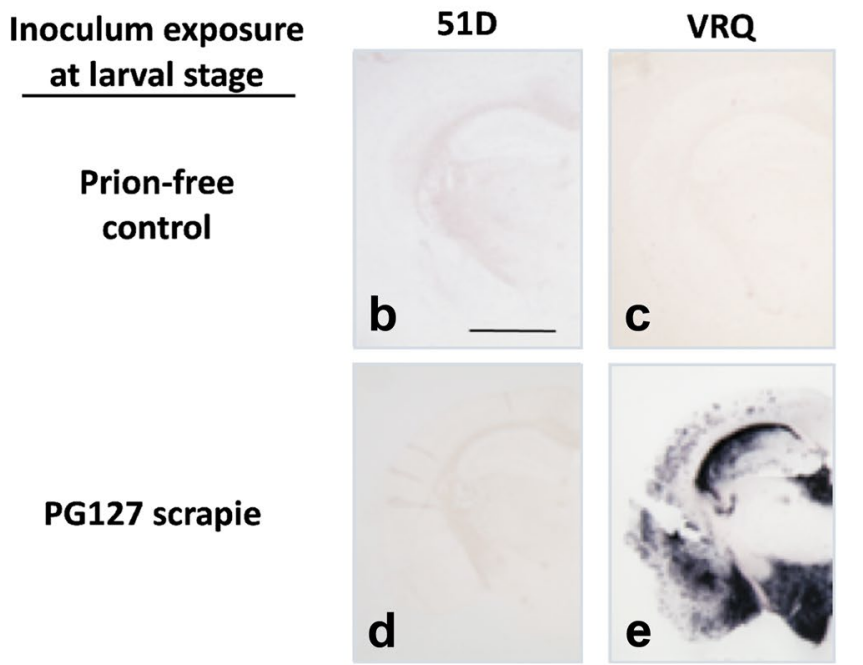


We also investigated whether the prion infectivity that accumulates in VRQ ovine PrP Drosophila could be serially propagated in the same fly line (Thackray et al. 2018). To do so, head homogenate from scrapie-infected 30-dayold adult VRQ ovine PrP or 51D Drosophila (first passage flies) was inoculated into fresh VRQ ovine PrP Drosophila (second passage flies) at the larval stage. Second passage VRQ ovine PrP Drosophila were allowed to hatch, and head homogenate prepared from groups of flies euthanised at 5 and 30 days of age was inoculated into tg338 mice in order to assess prion infectivity in these samples. Mice that received head homogenate from 30-day-old second passage VRQ ovine PrP Drosophila showed 100\% attack rate for clinical signs of mouse prion disease and an incubation period of $89 \pm 4$ days. The brains of clinically affected mice were characterised by PK-resistant PrP27-30 evidenced by SDS PAGE/western blot and the typical distribution of $\mathrm{PrP}^{\mathrm{Sc}}$ in PG127 scrapie-inoculated tg338 mice shown by PET blot analysis. No clinical signs were observed, and no abnormal PrP accumulated in tg338 mice inoculated with 5-day-old second passage VRQ PrP Drosophila head homogenate or from second passage VRQ PrP Drosophila exposed to first passage 51D control flies. These results demonstrate that mammalian prions can be serially propagated in VRQ PrP Drosophila following experimental inoculation of fly head homogenate. Collectively, these data unequivocally demonstrated that infectious ovine prions replicate and progressively accumulate in scrapie-exposed VRQ ovine PrP transgenic Drosophila.

\section{Preservation of prion strain phenotypes in Drosophila}

The molecular components and cellular machinery necessary to generate infectious neurotoxic prions remain undefined (Supattapone 2014). $\operatorname{PrP}^{\mathbf{C}}$ is ubiquitously expressed and well conserved in mammalian hosts, and it is possible that this group of species is permissive for prion propagation because they have co-evolved specific co-factors necessary for prion protein misfolding and replication. We tested this hypothesis by determining whether authentic prion propagation occurred in Drosophila melanogaster, an invertebrate phylogenetically separated from mammals by millions of years of divergent evolution and that lacks the presence of an orthologous PrP gene in its genome (Rivera-Milla et al. 2006).

We performed fly-to-mouse transmission experiments in $\operatorname{tg} 338$ mice (Thackray et al. 2018) using a panel of ovine prion strains characterised by unique incubation times and PK-resistant PrP27-30 molecular profile following selection in ovine PrP transgenic mice (Thackray et al. 2011, 2012a). Accordingly, we exposed VRQ or ARQ ovine PrP Drosophila at the larval stage to ovine prions isolated in VRQ or
ARQ ovine PrP mice, respectively. Collectively, these flies were susceptible to all of the ovine prion strains as shown by development of an accelerated decline in locomotor ability of adult flies (Thackray et al. 2018). These data implied that prion strain phenotype was conserved during propagation in PrP Drosophila. The severity of the neurotoxic phenotype in VRQ ovine PrP Drosophila induced by a 'short' incubation time ovine prion strain (tg338-passaged PG127, also known as $\mathrm{G}_{\mathbf{3 3 8}}$ ) was greater than that induced by a 'long' incubation time strain $\left(\mathrm{Apl}_{\mathbf{3 3 8}}\right)$ as seen by data in Fig. 5. This implies that the pathogenic determinants of different prion strains manifest themselves in mice and Drosophila.

We next used serial passage in $\operatorname{tg} 338$ mice to perform comparative prion strain typing studies between each original prion strain isolated in PrP transgenic mice and these prion strains propagated in ovine PrP Drosophila. The experiments showed that the disease phenotypes observed in $\operatorname{tg} 338$ mice inoculated with the original prion strains were similar to those obtained following inoculation with the equivalent prion strain propagated in ovine PrP Drosophila as shown by representative data in Table 1 (Thackray et al. 2018). In addition, the molecular profile of PK-resistant $\mathrm{PrP}^{\mathrm{Sc}}$ and the vacuolar lesion profile in the brains of $\operatorname{tg} 338$ mice inoculated with the original ovine prions and those propagated in PrP Drosophila were indistinguishable.

Collectively, these data demonstrated that the biological properties of distinct ovine prion strains were maintained after their propagation in ovine PrP Drosophila. The observations imply that molecular and cellular co-factors necessary for strain-specific prion propagation are conserved between phylogenetically diverse species and are not unique to mammalian hosts.

\section{Sensitive detection of mammalian prions by Drosophila}

We compared the sensitivity of PrP Drosophila to detect mammalian prions to that achieved by mice, the most commonly used mammalian species for this purpose, and to that obtained with in vitro PMCA.

We first compared the sensitivity of VRQ ovine PrP Drosophila to detect sheep scrapie prion infectivity and the tg338 mouse line, which is also transgenic for VRQ ovine PrP. To do so, the locomotor ability of adult VRQ ovine PrP Drosophila was assessed by a negative geotaxis climbing assay after exposure at the larval stage to a dilution series of classical scrapie-infected sheep brain homogenate (Thackray et al. 2016). A significant decline in adult VRQ ovine PrP Drosophila locomotor ability was induced by dilutions of prion inoculum in the range $10^{-2}-10^{-10}$, which diminished upon exposure to increasing dilution of prion inoculum. In contrast, the $\operatorname{tg} 338$ mouse line only detected dilutions 


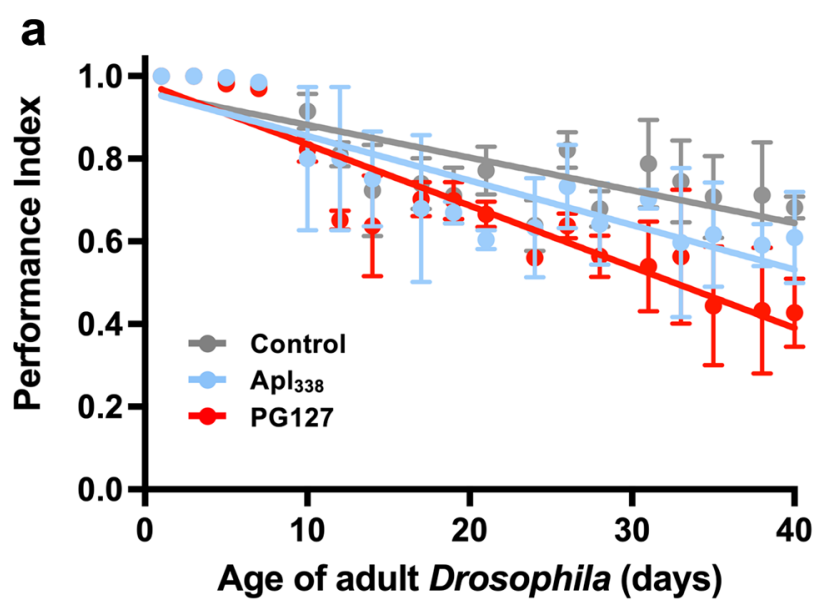

Fig. 5 Prion-induced toxicity in scrapie-exposed $\operatorname{PrP}$ transgenic Drosophila. Adult Actin $\times$ VRQ ovine PrP (a) or Actin $\times$ control 51D (b). Drosophila were assessed for their locomotor ability by a negative geotaxis climbing assay following exposure at the larval stage to PG127 (red line), $\mathrm{Apl}_{338}$ (light blue line) ovine scrapie strains derived

of the same prion inoculum in the range from neat to $10^{-5}$ (Andreoletti et al. 2011). These observations showed that VRQ ovine PrP Drosophila has a greater sensitivity for ovine prions compared to tg 338 mice.

We next determined the sensitivity of bovine PrP Drosophila to detect classical BSE prion infectivity. We first used PMCA to detect prion-seeding activity in adult Drosophila exposed to dilutions of classical BSE inoculum at the larval stage (Thackray et al. 2021). Prion-seeding activity was detected in head homogenate prepared from classical BSEexposed bovine PrP Drosophila aged $\geq 20$ days, and the sensitivity of detection progressively increased as the flies aged. For example, prion-seeding activity was detected in head homogenate of 20-day-old adult Drosophila after larval exposure to $\leq 10^{-8}$ dilution of classical BSE-infected bovine

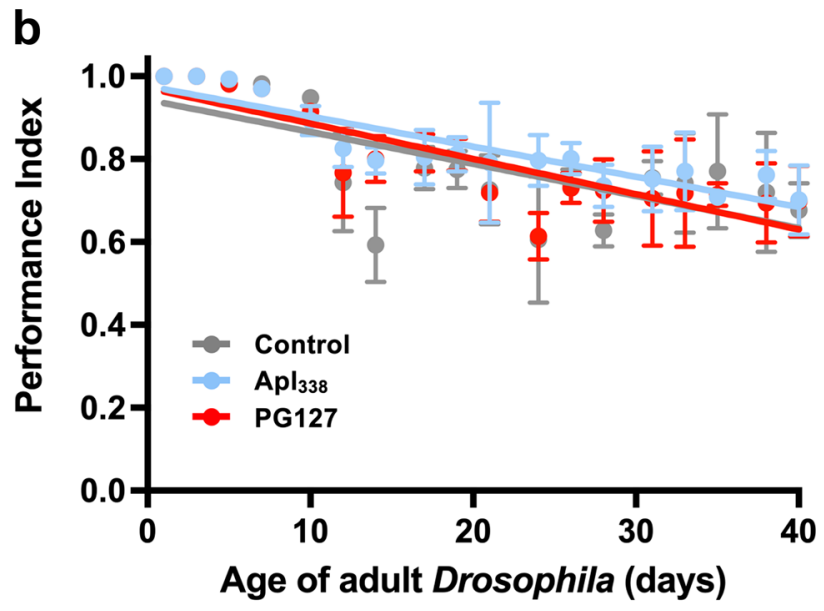

in tg338 mice (VRQ ovine PrP transgenic) or prion-free (grey line) $\operatorname{tg} 338$ mouse brain homogenate. The data shown are linear regression plots of the mean performance index \pm SD for three groups of flies per time point calculated. (Modified from Thackray et al., Brain, 2018, 141: pp2700-2710, supplementary data)

brain material, while 40-day-old flies were PMCA-positive after exposure to $\leq 10^{-14}$ dilution of the same inoculum. We also assessed the sensitivity of bovine PrP Drosophila for classical BSE prion detection by way of negative geotaxis and survival assays. After hatching, adult bovine PrP Drosophila showed accelerated decline in climbing ability compared to control treated flies, which became progressively more severe with age but decreased with increasing dilution of classical BSE inoculum. A significant response was seen following inoculation with $\leq 10^{-12}$ dilution of classical BSEinfected bovine brain material.

The median survival time of bovine PrP Drosophila exposed to classical BSE-infected bovine brain homogenate was reduced compared to the response seen after exposure to control prion-free inoculum, which progressively
Table 1 Scrapie strains retain transmission properties after passage in PrP transgenic Drosophila

\begin{tabular}{|c|c|c|c|c|c|c|}
\hline \multirow[b]{3}{*}{ Scrapie strain } & \multirow{2}{*}{\multicolumn{2}{|c|}{$\begin{array}{l}\text { Original strain isolated in } \\
\operatorname{tg} 338 \text { mice }\end{array}$}} & \multicolumn{4}{|c|}{ Drosophila-passaged strain isolated in tg 338 mice } \\
\hline & & & \multicolumn{2}{|c|}{ First passage } & \multicolumn{2}{|c|}{ Second passage } \\
\hline & Attack rate & IP & Attack rate & IP & Attack rate & IP \\
\hline PG127 & $6 / 6$ & $61 \pm 2$ & $6 / 6$ & $87 \pm 4$ & $6 / 6$ & $59 \pm 1$ \\
\hline $\mathrm{Apl}_{338}$ & $6 / 6$ & $631 \pm 83$ & $3 / 5$ & $642 \pm 57$ & $5 / 5$ & $766 \pm 125$ \\
\hline
\end{tabular}

The ovine classical scrapie prion strains PG127 and $\mathrm{Apl}_{338}$ (isolated in ovine VRQ tg338 mice) were transmitted to tg338 ovine PrP transgenic mice. In parallel, Actin $\times$ VRQ PrP Drosophila were exposed to the PG127 and $\mathrm{Apl}_{338}$, prion strains at the larval stage. Head homogenates were prepared from adult flies aged 30 days and serially transmitted in tg 338 mice (two iterative passages) by intracerebral inoculation. Mice were euthanised when they showed clinical signs of prion infection and after 250 days for those that did not develop clinical disease. Mice were considered positive for prion disease when PK-resistant PrP27-30 was detected in brain tissue by western blot. The attack rate (number of prion positive mice/total number of mice inoculated) is reported for each treatment group. The incubation period (IP) for inoculated mice, which represents the mean time from inoculation to euthanasia for each inoculated group of animals, is reported in days \pm SD. (Updated from Thackray et al., Brain, (2018), 141: pp. 2700-2710) 
lengthened upon exposure to increasing dilution of inoculum as shown by the data in Fig. 6. Significant accelerated loss of survival by adult bovine PrP Drosophila was observed after exposure of larvae to $\leq 10^{-12}$ dilution of classical BSE-infected bovine brain material. Collectively, these different assays show that the limit of sensitivity of bovine PrP Drosophila for detection of classical BSE was in the range of $10^{-12}-10^{-14}$ dilution of bovine prioninfected brain material (Thackray et al. 2021).

We subsequently established the level of sensitivity of bovine PrP transgenic mice and in vitro PMCA for the same classical BSE inoculum used to infect bovine PrP Drosophila (Thackray et al. 2021). When a dilution series of the classical BSE inoculum was inoculated intracerebrally into tg110 bovine PrP transgenic mice (Castilla et al. 2003), positive transmission was observed in animals exposed to $\leq 10^{-4}$ dilution of bovine prion-infected brain material. A second dilution series of the classical BSE isolate was used as seed in PMCA reactions that were subsequently tested for the presence of PK-resistant $\operatorname{PrP}^{\mathrm{Sc}}$. Positive PMCA activity was observed in reaction tubes seeded with dilutions $\leq 10^{-7}$ of the classical BSE isolate. Collectively, these data reveal that bovine PrP Drosophila are $10^{6}$-fold more sensitive in identifying classical BSE compared to the bovine PrP mouse bioassay and $10^{5}$-fold more sensitive than PMCA.

For appropriate biosecurity, studies with BSE, chronic wasting disease (CWD) or CJD-inoculated Drosophila require the flies to be maintained at containment level 3 for prion research, an enhanced level of safety above the containment level 2 used for the sheep scrapie studies. In this manner, PrP transgenic Drosophila can be used to begin to address important questions on the pathogenic potential of known and possible zoonotic prions such as CWD in cervids.

\section{Bioassay of prion-infected blood plasma in Drosophila}

Our finding that PrP Drosophila showed a high sensitivity for detection of mammalian prions led us to speculate that this invertebrate host could detect the apparent low titre of prion infectivity in the blood of prion-diseased animals. In order to test this hypothesis, we used VRQ ovine PrP Drosophila to bioassay known prion-positive blood samples from VRQ PrP homozygous sheep experimentally infected with classical scrapie (Thackray et al. 2016). We chose to bioassay sheep plasma as this blood fraction is reported to contain a low level of prion infectivity and is notoriously difficult to assess by conventional prion bioassay (Lacroux et al. 2012).

Ovine PrP Drosophila were exposed at the larval stage to a dilution series of plasma isolated from a sheep with experimental clinical scrapie disease, and the locomotor ability of adult Drosophila was assessed by a negative geotaxis climbing assay (Thackray et al. 2016). Ovine PrP Drosophila demonstrated an accelerated decline in locomotor ability soon after hatching following larval exposure to scrapie-infected sheep plasma compared to the response seen after exposure to scrapie-free sheep plasma. The rate of decline in locomotor ability diminished with exposure to increasing dilution of scrapie-infected plasma, indicative of titration of a particulate transmissible moiety, a characteristic feature of the infectious scrapie agent (Stamp 1962). Strikingly, the limit of detection in ovine PrP Drosophila was a dilution of $\leq 10^{-6}$ of plasma from sheep with experimental-induced clinical scrapie.

We next investigated whether PrP transgenic Drosophila could detect plasma from sheep with natural scrapie. The donor animals were VRQ PrP homozygous sheep born and maintained in a flock endemic for natural classical scrapie (Dexter et al. 2009). Blood samples were collected from
Fig. 6 Accelerated loss of survival of classical BSE-exposed bovine PrP Drosophila. Adult Elav $\times$ bovine PrP Drosophila were assessed for survival following exposure at the larval stage to $10^{-2}-10^{-20}$ dilutions of classical BSE-infected bovine brain material. Control inoculum was a $10^{-2}$ dilution of prion-free bovine brain material (control $10^{-2}$ ). The number of surviving flies was recorded three times a week and the data shown as Kaplan-Meier plots. $\mathrm{C}-\mathrm{BSE}=$ classical BSE. (Thackray et al., J. Biol. Chem., 2021, 297, 100,878)

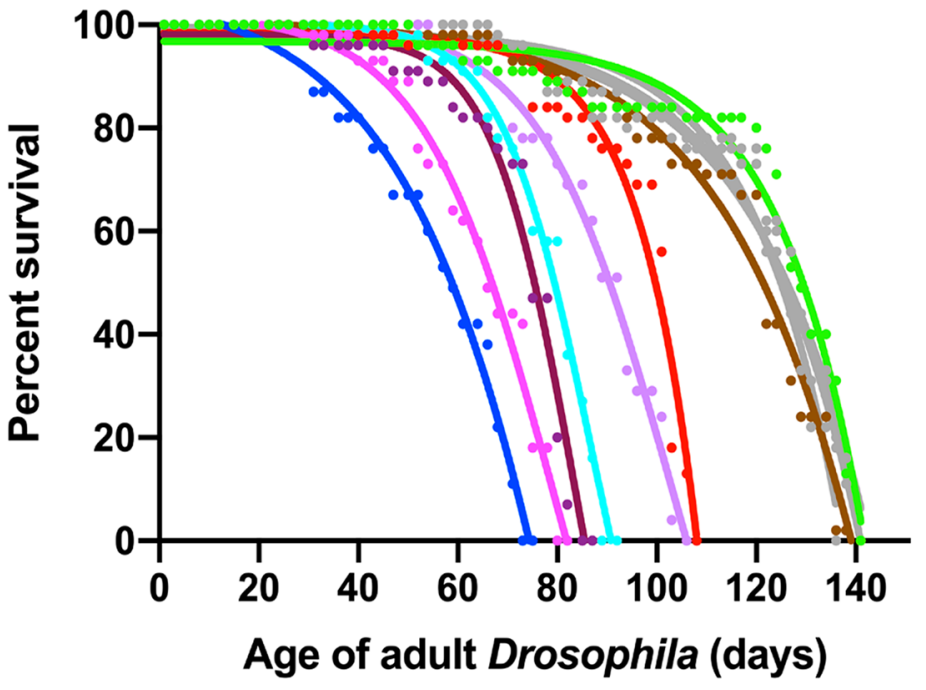


sheep shortly after birth and then at regular intervals until the animals showed clinical signs of terminal scrapie disease when they were euthanised. All of the euthanised blood donor sheep were shown to be positive for scrapie disease by routine testing for disease-associated $\operatorname{PrP}$, and the mean survival time of the animals was $695 \pm 25$ days. We assessed the locomotor ability of adult Drosophila, transgenic for a cytoplasmic form of VRQ ovine PrP [VRQ(cyt)] by a negative geotaxis climbing assay after larval exposure to plasma from sheep with natural scrapie (Thackray et al. 2016).

Adult VRQ(cyt) PrP transgenic Drosophila showed no accelerated decline in locomotor activity after exposure at the larval stage to plasma prepared from natural scrapieaffected sheep aged 3 months compared to that seen following exposure to control plasma. However, a significant response was seen with plasma from donor animals aged $\geq 6$ months that was most pronounced in terminal stage disease samples. These observations demonstrated the ability of PrP transgenic Drosophila to detect prion-infected plasma samples from asymptomatic scrapie-infected sheep since clinical signs of the disease were not evident until these animals were $\geq 20$ months of age (Thackray et al. 2016).

\section{Transcriptional signature of prion-induced neurotoxicity in Drosophila}

An important goal in prion biology is to establish the mechanism of prion-induced neurotoxicity as this will underpin therapeutic and control strategies for human and animal prion diseases. Despite significant advances in this area (Hwang et al. 2009; Moreno et al. 2012; Scheckel et al. 2020; Sorce et al. 2020; Vincenti et al. 2015), understanding this process remains to be fully defined. We reasoned that Drosophila, a genetically well-defined animal model, provided a novel system to probe the identity of cellular and molecular pathways associated with prion-induced neurotoxicity.

Accordingly, we performed RNA-Seq-based transcriptome analysis on 5 and 40-day-old adult fly head homogenate prepared from VRQ ovine PrP Drosophila and the control 51D fly line after larval exposure to either scrapie-infected or control prion-free sheep brain homogenate (Thackray et al. 2020). Following prion exposure at the larval stage, 5-day-old adult VRQ ovine PrP Drosophila lack a significant locomotor defect, while 40-day-old adult flies showed an accelerated decline in locomotor activity (Thackray et al. 2018), and therefore represent pre-clinical and clinical time points, respectively.

Collectively, a total of 9672 Drosophila genes were detected in prion-infected and control fly samples harvested at 5 days and 40 days post hatching (Thackray et al. 2020). This represented expression of $>61.7 \%$ of the Drosophila melanogaster genome during the course of the experiment.
Temporal and quantitative differentially expressed gene expression changes were seen in prion-exposed PrP Drosophila that were distinct from those in similarly treated 51D flies. This implied that the gene changes seen in scrapie exposed ovine PrP Drosophila were prion-induced and not simply an effect of these flies ageing. We performed pathway enrichment analysis using combined lists of differentially expressed genes in prion-exposed PrP Drosophila on both days 5 and 40 in order to obtain unbiased predictions of cellular and biochemical events perturbed as a consequence of prion exposure (Thackray et al. 2020). We subsequently inspected the overrepresented pathways for genes either upor down-regulated at different time points in order to predict when particular cellular functions were enhanced or suppressed following prion infection in the fly.

Up-regulation of genes involved with cell cycle activity and DNA damage response (DDR) was identified in 5-day-old prion-exposed adult PrP Drosophila after larval exposure to scrapie material. At this time point, top-ranked up-regulated functions were cell cycle activity and DNA damage regulation, together with functions that control cell cycle progression, namely GADD45 and ataxia telangiectasia mutated (ATM) signalling (Liebermann and Hoffman 2008). Usually, post mitotic neurons do not participate in cell cycle activity as this is considered to be detrimental to these cells (Frank and Tsai 2009). In this context, post mitotic neurons may have the potential to revert to a dedifferentiated state, which might be linked to activation of apoptotic pathways and concomitant neurodegeneration (Arendt 2001; Arendt et al. 2000; Herrup and Yang 2007).

Down-regulation of eIF2 signalling gene expression was identified in 40-day-old ovine PrP Drosophila, previously exposed to scrapie material at the larval stage. Prionexposed PrP Drosophila at this time point showed a dramatic down-regulation of multiple genes of the eIF2 signalling pathway, including those that encoded $40 \mathrm{~S}$ and $60 \mathrm{~S}$ ribosomal proteins or genes that encoded components of various translational initiation cofactors, including eIF1, eIF2, eIF3 and eIF4. Since eIF2 signalling is a major regulator of initiation of mRNA translation (Kapur et al. 2017), downregulation of this pathway was indicative of suppression of protein synthesis in prion-exposed Drosophila. Neurons are highly dependent upon sustained and efficient mRNA translation in order to undergo two important processes, namely neurotransmitter release and synaptic plasticity.

The integrated stress response (Pakos-Zebrucka et al. 2016) or the unfolded protein response (Ron 2002) is an important regulator of eIF2 signalling. This stress response inhibits general protein synthesis through eIF $2 \alpha$ phosphorylation, and subsequent sequestration of the eIF $2 \alpha$ guanine nucleotide exchange factor eIF2B. The fly gene Gcn2, which encodes a kinase that phosphorylates eIF2 $\alpha$, was upregulated in prion-exposed PrP Drosophila, which suggests 
Fig. 7 Model for prion-induced neurotoxicity in PrP transgenic Drosophila. Proposed major cellular events, together with representative participating genes (shown in brackets), associated with prion-induced neurotoxicity in PrP transgenic Drosophila. (Modified from Thackray et al., Biochem. J., 2020, 477: pp833-852)

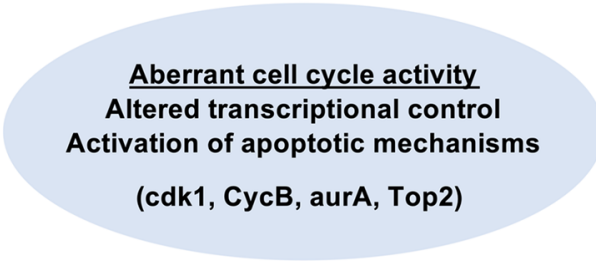

Loss of mitochondrial homeostasis Reduced ATP production

(COX6B, Cyt-c1, ATP-syn, Sod 2)

Repression of protein synthesis Activation of unfolded protein response

(InR, AG01, elF4A, elF2 $\gamma$ )
Day 5

Age of prion-infected adult PrP transgenic Drosophila activation of the integrated stress response in these flies. This observation correlates with studies in cells (Roffe et al. 2010) and mice (Moreno et al. 2012) that show that prion disease progression triggers activation of the PERK/eIF $2 \alpha$ branch of the unfolded protein response with its subsequent block on protein translation.

A second major signalling pathway that displayed differential gene expression in prion-exposed PrP Drosophila was the mTOR signalling pathway (Thackray et al. 2020). mTOR mediates an important role in the regulation of autophagy, a process that serves to prevent the accumulation of aberrantly toxic protein aggregates or organelles (Abdelaziz et al. 2019). We found that 40-day-old prion-exposed $\operatorname{PrP}$ Drosophila were characterised by marked changes in gene expression for some genes of the mTOR pathway. In addition to down-regulated eIF and ribosomal subunit genes, several genes were up-regulated including Dsorl (Tsuda et al. 1993); $L k 6$, a serine/threonine-protein kinase that interacts with mitogen-activated protein kinase 1 MAPk1/ ERK2 (Cargnello and Roux 2011) and Pkc98E, a regulatory protein kinase activated by diacylglycerol or $\mathrm{Ca}^{2+}$ (Lipp and Reither 2011).

Mitochondrial dysfunction was identified by Ingenuity Pathway Analysis as the top toxicity pathway in prionexposed Drosophila. It was found that prion-exposed 40-day-old adult VRQ ovine PrP Drosophila, exposed to scrapie at the larval stage, were characterised by downregulation of genes encoding principal components of the electron transport chain including NADH dehydrogenase, ATP synthase and various anti-oxidants including superoxidase dismutase-2 and glutaredoxin 1 . Neurons are vulnerable to mitochondrial dysfunction because of the need to satisfy the large energy demands of synaptic development, transmission and plasticity. Mitochondrial dysfunction is a feature of hamster (Choi et al. 1998) and mouse (Keller et al. 2019;
Siskova et al. 2010) models of prion disease. In addition, down-regulation of mRNA and protein levels of mitochondrial proteins have been reported in post-mortem tissues of Creutzfeldt-Jakob disease (CJD) patients (Ansoleaga et al. 2016).

Based on these observations, we speculate that following initial prion infection at the larval stage, subsequent $\mathrm{PrP}^{\mathrm{Sc}}$ accumulation within Drosophila neurons has an adverse effect upon critical cellular processes, that in turn leads to a genotoxic effect with resultant dysregulated gene expression and aberrant cell cycle activity coupled with the activation of apoptotic mechanisms (Thackray et al. 2020). We further speculate that these early prion-induced events drive a loss of neuronal mitochondrial homeostasis and a repression of protein synthesis as neurons attempt to accommodate the cellular stress associated with PrP misfolding, which is summarised in Fig. 7. We are unable to differentiate whether the proposed loss of mitochondrial homeostasis, which will invariably be accompanied by a reduction in ATP production, is the stimulus for repression of protein synthesis or whether loss of protein synthesis drives loss of normal mitochondrial status. However, our use of Drosophila, a genetically well-defined tractable experimental host amenable to silencing and overexpression of specific genes, will allow us to begin to attempt to differentiate between these possibilities.

\section{Concluding comments}

We have shown that PrP transgenic Drosophila provide paradigm shift in the bioassay of transmissible mammalian prions. This novel invertebrate animal model shows robust and extremely sensitive detection of mammalian prion infectivity in a reasonably high-throughput and rapid, 
cost-effective manner. The facile nature of transgenesis in Drosophila renders this host amenable to the generation of flies transgenic for different species forms of mammalian PrP by tractable and timely means, in order to bioassay prions from a wide variety of prion diseases. This is particularly relevant given the emergence of new prion diseases in animals, such as camel prion disease, together with the new reservoirs of CWD in cervids that pose fresh challenges to human food safety since their zoonotic potential is unknown. Accordingly, more prion bioassays will be required to fully determine the relative risk these new prion disease occurrences present to the human food chain and PrP transgenic Drosophila provide the ideal host for this role.

Given the infectious nature of the transmissible prion agent, sensitive detection of this pathogen is required to characterise the spread of these diseases within affected populations. The detection of mammalian prions by PrP transgenic Drosophila was more sensitive than that achieved by in vivo bioassay in mice and in vitro PMCA. PrP transgenic Drosophila were sufficiently sensitive to be able to detect prion-infected blood from sheep with preclinical scrapie disease and in a timeframe significantly shorter than that achievable by bioassay in mammalian species, including transfusion in the natural host. This provides the basis for development of a much needed versatile and efficient blood test for mammalian prion disease based on the use of PrP transgenic Drosophila.

Significantly, we have shown that mammalian prions propagate faithfully in PrP transgenic Drosophila with preservation of prion strain phenotype. This highlights that the cellular and molecular components required for prion protein misfolding and prion propagation are maintained between Drosophila and mammalian species, despite the fact that this invertebrate does not normally express PrP. This in turn has allowed the cellular processes and molecular components associated with prion-induced neurotoxicity to be investigated in the fly through RNASeq analysis. This approach revealed candidate pathways and processes, e.g. eIF2 signalling and mitochondrial dysfunction, that may function both as biomarkers of prion infection, and potential therapeutic targets. The extensive molecular and transgenic repertoire of Drosophila will allow candidate genetic modifiers of prioninduced neurotoxicity to be further validated through RNAimediated gene silencing or transgenic overexpression during prion infection in PrP Drosophila.

Overall, we have established PrP transgenic Drosophila as a new animal system that will make a significant contribution to the understanding of mammalian prion biology.

Acknowledgements We thank our former PhD students who contributed towards the development of this Drosophila model. We acknowledge the Fly Facility, Department of Genetics, University of Cambridge.
Funding The study was financially supported by the National Centre for the Replacement, Refinement \& Reduction of Animals in Research (NC3Rs) and the Biotechnology and Biological Sciences Research Council (BBSRC).

\section{Declarations}

Conflict of interest The authors declare no competing interests.

Open Access This article is licensed under a Creative Commons Attribution 4.0 International License, which permits use, sharing, adaptation, distribution and reproduction in any medium or format, as long as you give appropriate credit to the original author(s) and the source, provide a link to the Creative Commons licence, and indicate if changes were made. The images or other third party material in this article are included in the article's Creative Commons licence, unless indicated otherwise in a credit line to the material. If material is not included in the article's Creative Commons licence and your intended use is not permitted by statutory regulation or exceeds the permitted use, you will need to obtain permission directly from the copyright holder. To view a copy of this licence, visit http://creativecommons.org/licenses/by/4.0/.

\section{References}

Abdelaziz DH, Abdulrahman BA, Gilch S, Schatzl HM (2019) Autophagy pathways in the treatment of prion diseases. Curr Opin Pharmacol 44:46-52

Andreoletti O, Orge L, Benestad SL, Beringue V, Litaise C, Simon S, Le Dur A, Laude H, Simmons H, Lugan S et al (2011) Atypical/Nor98 scrapie infectivity in sheep peripheral tissues. PLoS Pathog 7:e1001285

Ansoleaga B, Garcia-Esparcia P, Llorens F, Hernandez-Ortega K, Carmona Tech M, Antonio Del Rio J, Zerr I, Ferrer I (2016) Altered mitochondria, protein synthesis machinery, and purine metabolism are molecular contributors to the pathogenesis of Creutzfeldt-Jakob disease. J Neuropathol Exp Neurol 75:755-769

Arendt T (2001) Alzheimer's disease as a disorder of mechanisms underlying structural brain self-organization. Neuroscience 102:723-765

Arendt T, Holzer M, Stobe A, Gartner U, Luth HJ, Bruckner MK, Ueberham U (2000) Activated mitogenic signaling induces a process of dedifferentiation in Alzheimer's disease that eventually results in cell death. Ann N Y Acad Sci 920:249-255

Auluck PK, Chan HY, Trojanowski JQ, Lee VM, Bonini NM (2002) Chaperone suppression of alpha-synuclein toxicity in a Drosophila model for Parkinson's disease. Science 295:865-868

Babelhadj B, Di Bari MA, Pirisinu L, Chiappini B, Gaouar SBS, Riccardi G, Marcon S, Agrimi U, Nonno R, Vaccari G (2018) Prion disease in dromedary camels, Algeria. Emerg Infect Dis 24:1029-1036

Beekes M, Baldauf E, Diringer H (1996) Sequential appearance and accumulation of pathognomonic markers in the central nervous system of hamsters orally infected with scrapie. J Gen Virol 77(Pt 8):1925-1934

Benestad SL, Mitchell G, Simmons M, Ytrehus B, Vikoren T (2016) First case of chronic wasting disease in Europe in a Norwegian free-ranging reindeer. Vet Res 47:88

Benestad SL, Sarradin P, Thu B, Schonheit J, Tranulis MA, Bratberg B (2003) Cases of scrapie with unusual features in Norway and designation of a new type, Nor98. Vet Rec 153:202-208

Beringue V, Bencsik A, Le Dur A, Reine F, Lai TL, Chenais N, Tilly G, Biacabe AG, Baron T, Vilotte JL et al (2006) Isolation from 
cattle of a prion strain distinct from that causing bovine spongiform encephalopathy. PLoS Pathog 2:e112

Biacabe AG, Laplanche JL, Ryder S, Baron T (2004) Distinct molecular phenotypes in bovine prion diseases. EMBO Rep 5:110-115

Bischof J, Maeda RK, Hediger M, Karch F, Basler K (2007) An optimized transgenesis system for Drosophila using germline-specific phiC31 integrases. Proc Natl Acad Sci U S A 104:3312-3317

Bolton DC, McKinley MP, Prusiner SB (1982) Identification of a protein that purifies with the scrapie prion. Science 218:1309-1311

Bolton DC, Rudelli RD, Currie JR, Bendheim PE (1991) Copurification of Sp33-37 and scrapie agent from hamster brain prior to detectable histopathology and clinical disease. J Gen Virol 72(Pt 12):2905-2913

Brandner S, Jaunmuktane Z (2017) Prion disease: experimental models and reality. Acta Neuropathol 133:197-222

Bueler H, Aguzzi A, Sailer A, Greiner RA, Autenried P, Aguet M, Weissmann C (1993) Mice devoid of PrP are resistant to scrapie. Cell 73:1339-1347

Cargnello M, Roux PP (2011) Activation and function of the MAPKs and their substrates, the MAPK-activated protein kinases. Microbiol Mol Biol Rev 75:50-83

Cartoni C, Schinina ME, Maras B, Nonno R, Vaccari G, Di Baria MA, Conte M, Liu QG, Lu M, Cardone F et al (2005) Identification of the pathological prion protein allotypes in scrapieinfected heterozygous bank voles (Clethrionomys glareolus) by high-performance liquid chromatography-mass spectrometry. J Chromatogr A 1081:122-126

Castilla J, Gutierrez Adan A, Brun A, Pintado B, Ramirez MA, Parra B, Doyle D, Rogers M, Salguero FJ, Sanchez C et al (2003) Early detection of PrPres in BSE-infected bovine PrP transgenic mice. Arch Virol 148:677-691

Chandler RL (1961) Encephalopathy in mice produced by inoculation with scrapie brain material. Lancet 1:1378-1379

Choi JK, Jeon YC, Lee DW, Oh JM, Lee HP, Jeong BH, Carp RI, Koh YH, Kim YS (2010) A Drosophila model of GSS syndrome suggests defects in active zones are responsible for pathogenesis of GSS syndrome. Hum Mol Genet 19:4474-4489

Choi SI, Ju WK, Choi EK, Kim J, Lea HZ, Carp RI, Wisniewski HM, Kim YS (1998) Mitochondrial dysfunction induced by oxidative stress in the brains of hamsters infected with the $263 \mathrm{~K}$ scrapie agent. Acta Neuropathol 96:279-286

Clouscard C, Beaudry P, Elsen JM, Milan D, Dussaucy M, Bounneau C, Schelcher F, Chatelain J, Launay JM, Laplanche JL (1995) Different allelic effects of the codons 136 and 171 of the prion protein gene in sheep with natural scrapie. J Gen Virol 76(Pt 8):2097-2101

Comoy EE, Casalone C, Lescoutra-Etchegaray N, Zanusso G, Freire S, Marce D, Auvre F, Ruchoux MM, Ferrari S, Monaco S et al (2008) Atypical BSE (BASE) transmitted from asymptomatic aging cattle to a primate. PLoS One 3:e3017

Comoy EE, Mikol J, Luccantoni-Freire S, Correia E, Lescoutra-Etchegaray N, Durand V, Dehen C, Andreoletti O, Casalone C, Richt JA et al (2015) Transmission of scrapie prions to primate after an extended silent incubation period. Sci Rep 5:11573

Crozet C, Flamant F, Bencsik A, Aubert D, Samarut J, Baron T (2001) Efficient transmission of two different sheep scrapie isolates in transgenic mice expressing the ovine PrP gene. J Virol 75:5328-5334

Cullié J, Chelle PL (1936) Pathologie animale : la maladie dite de la tremblante du mouton est-elle inoculable? Comptes Rendus De L'académie Des Sciences (D) 203:1552-1554

Deleault NR, Dolph PJ, Feany MB, Cook ME, Nishina K, Harris DA, Supattapone S (2003) Post-transcriptional suppression of pathogenic prion protein expression in Drosophila neurons. J Neurochem 85:1614-1623
Dexter G, Tongue SC, Heasman L, Bellworthy SJ, Davis A, Moore SJ, Simmons MM, Sayers AR, Simmons HA, Matthews D (2009) The evaluation of exposure risks for natural transmission of scrapie within an infected flock. BMC Vet Res 5:38

Feany MB, Bender WW (2000) A Drosophila model of Parkinson's disease. Nature 404:394-398

Fernandez-Funez P, Casas-Tinto S, Zhang Y, Gomez-Velazquez M, Morales-Garza MA, Cepeda-Nieto AC, Castilla J, Soto C, Rincon-Limas DE (2009) In vivo generation of neurotoxic prion protein: role for hsp70 in accumulation of misfolded isoforms. PLoS Genet 5:e1000507

Fernandez-Funez P, Sanchez-Garcia J, Rincon-Limas DE (2017) Drosophila models of prionopathies: insight into prion protein function, transmission, and neurotoxicity. Curr Opin Genet Dev 44:141-148

Fernandez-Funez P, Zhang Y, Casas-Tinto S, Xiao X, Zou WQ, Rincon-Limas DE (2010) Sequence-dependent prion protein misfolding and neurotoxicity. J Biol Chem 285:36897-36908

Frank CL, Tsai LH (2009) Alternative functions of core cell cycle regulators in neuronal migration, neuronal maturation, and synaptic plasticity. Neuron 62:312-326

Fraser H, Dickinson AG (1968) The sequential development of the brain lesion of scrapie in three strains of mice. J Comp Pathol 78:301-311

Fulga TA, Elson-Schwab I, Khurana V, Steinhilb ML, Spires TL, Hyman BT, Feany MB (2007) Abnormal bundling and accumulation of F-actin mediates tau-induced neuronal degeneration in vivo. Nat Cell Biol 9:139-148

Gajdusek DC, Gibbs CJ, Alpers M (1966) Experimental transmission of a Kuru-like syndrome to chimpanzees. Nature 209:794-796

Gavin BA, Dolph MJ, Deleault NR, Geoghegan JC, Khurana V, Feany MB, Dolph PJ, Supattapone S (2006) Accelerated accumulation of misfolded prion protein and spongiform degeneration in a Drosophila model of Gerstmann-Straussler-Scheinker syndrome. J Neurosci 26:12408-12414

Gavin BA, Dolph MJ, Deleault NR, Geoghegan JC, Khurana V, Feany MB, Dolph PJ, Supattapone S (2008) Correction: accelerated accumulation of misfolded prion protein and Spongiform degeneration in a Drosophila model of Gerstmann-StrausslerScheinker syndrome. J Neurosci 28:np

Gibbs CJ Jr, Amyx HL, Bacote A, Masters CL, Gajdusek DC (1980) Oral transmission of kuru, Creutzfeldt-Jakob disease, and scrapie to nonhuman primates. J Infect Dis 142:205-208

Gibbs CJ Jr, Gajdusek DC (1972) Transmission of scrapie to the cynomolgus monkey (Macaca fascicularis). Nature 236:73-74

Glatzel M, Aguzzi A (2000) Peripheral pathogenesis of prion diseases. Microbes Infect 2:613-619

Goldmann W, Hunter N, Smith G, Foster J, Hope J (1994) PrP genotype and agent effects in scrapie: change in allelic interaction with different isolates of agent in sheep, a natural host of scrapie. J Gen Virol 75(Pt 5):989-995

Gordon WS (1946) Advances in veterinary research. Vet Rec 58:516-525

Green C, Levashina E, McKimmie C, Dafforn T, Reichhart JM, Gubb D (2000) The necrotic gene in Drosophila corresponds to one of a cluster of three serpin transcripts mapping at 43A1.2. Genetics 156:1117-1127

Greeve I, Kretzschmar D, Tschape JA, Beyn A, Brellinger C, Schweizer M, Nitsch RM, Reifegerste R (2004) Age-dependent neurodegeneration and Alzheimer-amyloid plaque formation in transgenic Drosophila. J Neurosci 24:3899-3906

Groschup MH, Buschmann A (2008) Rodent models for prion diseases. Vet Res 39:32

Herrup K, Yang Y (2007) Cell cycle regulation in the postmitotic neuron: oxymoron or new biology? Nat Rev Neurosci 8:368-378

Hill AF, Joiner S, Linehan J, Desbruslais M, Lantos PL, Collinge J (2000) Species-barrier-independent prion replication in 
apparently resistant species. Proc Natl Acad Sci U S A 97:10248-10253

Hunter N (1997) PrP genetics in sheep and the applications for scrapie and BSE. Trends Microbiol 5:331-334

Hunter N (2003) Scrapie and experimental BSE in sheep. Br Med Bull 66:171-183

Hwang D, Lee IY, Yoo H, Gehlenborg N, Cho JH, Petritis B, Baxter D, Pitstick R, Young R, Spicer D et al (2009) A systems approach to prion disease. Mol Syst Biol 5:252. https://doi.org/10.1038/ msb. 2009.10

Iijima K, Liu HP, Chiang AS, Hearn SA, Konsolaki M, Zhong Y (2004) Dissecting the pathological effects of human Abeta40 and Abeta42 in Drosophila: a potential model for Alzheimer's disease. Proc Natl Acad Sci U S A 101:6623-6628

Jendroska K, Heinzel FP, Torchia M, Stowring L, Kretzschmar HA, Kon A, Stern A, Prusiner SB, DeArmond SJ (1991) Proteinaseresistant prion protein accumulation in Syrian hamster brain correlates with regional pathology and scrapie infectivity. Neurology 41:1482-1490

Kang J, Lemaire HG, Unterbeck A, Salbaum JM, Masters CL, Grzeschik KH, Multhaup G, Beyreuther K, Muller-Hill B (1987) The precursor of Alzheimer's disease amyloid A4 protein resembles a cell-surface receptor. Nature 325:733-736

Kapur M, Monaghan CE, Ackerman SL (2017) Regulation of mRNA translation in neurons - a matter of life and death. Neuron 96:616-637

Keller G, Binyamin O, Frid K, Saada A, Gabizon R (2019) Mitochondrial dysfunction in preclinical genetic prion disease: a target for preventive treatment? Neurobiol Dis 124:57-66

Lacroux C, Vilette D, Fernandez-Borges N, Litaise C, Lugan S, Morel N, Corbiere F, Simon S, Simmons H, Costes P et al (2012) Prionemia and leukocyte-platelet-associated infectivity in sheep transmissible spongiform encephalopathy models. J Virol 86:2056-2066

Lasmezas CI, Deslys JP, Demaimay R, Adjou KT, Lamoury F, Dormont D, Robain O, Ironside J, Hauw JJ (1996) BSE transmission to macaques. Nature 381:743-744

Lasmezas CI, Deslys JP, Robain O, Jaegly A, Beringue V, Peyrin JM, Fournier JG, Hauw JJ, Rossier J, Dormont D (1997) Transmission of the BSE agent to mice in the absence of detectable abnormal prion protein. Science 275:402-405

Legname G, Baskakov IV, Nguyen HO, Riesner D, Cohen FE, DeArmond SJ, Prusiner SB (2004) Synthetic mammalian prions. Science 305:673-676

Lessing D, Bonini NM (2009) Maintaining the brain: insight into human neurodegeneration from Drosophila melanogaster mutants. Nat Rev Genet 10:359-370

Liebermann DA, Hoffman B (2008) Gadd45 in stress signaling. J Mol Signal 3:15

Lipp P, Reither G (2011) Protein kinase C: the "masters" of calcium and lipid. Cold Spring Harb Perspect Biol 3

Lu B, Vogel H (2009) Drosophila models of neurodegenerative diseases. Annu Rev Pathol 4:315-342

Luo L, Tully T, White K (1992) Human amyloid precursor protein ameliorates behavioral deficit of flies deleted for Appl gene. Neuron 9:595-605

Mabbott NA, MacPherson GG (2006) Prions and their lethal journey to the brain. Nat Rev Microbiol 4:201-211

Mallucci G, Dickinson A, Linehan J, Klohn PC, Brandner S, Collinge J (2003) Depleting neuronal PrP in prion infection prevents disease and reverses spongiosis. Science 302:871-874

Marchal I, Jarvis DL, Cacan R, Verbert A (2001) Glycoproteins from insect cells: sialylated or not? Biol Chem 382:151-159

Marsh JL, Thompson LM (2006) Drosophila in the study of neurodegenerative disease. Neuron 52:169-178

Marsh RF, Kincaid AE, Bessen RA, Bartz JC (2005) Interspecies transmission of chronic wasting disease prions to squirrel monkeys (Saimiri sciureus). J Virol 79:13794-13796
März L, Altmann F, Staudacher E, Kubelka V (1995) Protein glycosylation in insects. Elsevier, Amsterdam, The Netherlands

McKinley MP, Bolton DC, Prusiner SB (1983) A protease-resistant protein is a structural component of the scrapie prion. Cell 35:57-62

Min KT, Benzer S (1999) Preventing neurodegeneration in the Drosophila mutant bubblegum. Science 284:1985-1988

Miyazawa K, Emmerling K, Manuelidis L (2011) High CJD infectivity remains after prion protein is destroyed. J Cell Biochem 112:3630-3637

Moreno JA, Radford H, Peretti D, Steinert JR, Verity N, Martin MG, Halliday M, Morgan J, Dinsdale D, Ortori CA et al (2012) Sustained translational repression by eIF2alpha-P mediates prion neurodegeneration. Nature 485:507-511

Moreno JA, Telling GC (2017) Insights into mechanisms of transmission and pathogenesis from transgenic mouse models of prion diseases. Methods Mol Biol 1658:219-252

Murali A, Maue RA, Dolph PJ (2014) Reversible symptoms and clearance of mutant prion protein in an inducible model of a genetic prion disease in Drosophila melanogaster. Neurobiol Dis 67:71-78

Nonno R, Di Bari MA, Cardone F, Vaccari G, Fazzi P, Dell'Omo G, Cartoni C, Ingrosso L, Boyle A, Galeno R et al (2006) Efficient transmission and characterization of Creutzfeldt-Jakob disease strains in bank voles. PLoS Pathog 2:e12

Oesch B, Westaway D, Walchli M, McKinley MP, Kent SB, Aebersold R, Barry RA, Tempst P, Teplow DB, Hood LE et al (1985) A cellular gene encodes scrapie PrP 27-30 protein. Cell 40:735-746

Orge L, Lima C, Machado C, Tavares P, Mendonca P, Carvalho P, Silva J, Pinto ML, Bastos E, Pereira JC et al (2021) Neuropathology of animal prion diseases. Biomolecules 11

Pakos-Zebrucka K, Koryga I, Mnich K, Ljujic M, Samali A, Gorman AM (2016) The integrated stress response. EMBO Rep 17:1374-1395

Park Y, Kim W, Kim AY, Choi HJ, Choi JK, Park N, Koh EK, Seo J, Koh YH (2011) Normal prion protein in Drosophila enhances the toxicity of pathogenic polyglutamine proteins and alters susceptibility to oxidative and autophagy signaling modulators. Biochem Biophys Res Commun 404:638-645

Pattison IH (1965) In Slow, latent and temperate virus infections NINDB Monograph 2. In, Gajdusek DC, Gibbs CJ, Alpers MP (eds) (Washington, DC, USA: U.S. Government Printing Office), pp 249-257

Pattison IH, Millson GC (1960) Further observations on the experimental production of scrapie in goats and sheep. J Comp Pathol 70:182-193

Piper MD, Skorupa D, Partridge L (2005) Diet, metabolism and lifespan in Drosophila. Exp Gerontol 40:857-862

Prusiner SB (1982) Novel proteinaceous infectious particles cause scrapie. Science 216:136-144

Prusiner SB (2004) Prion biology and diseases, 2nd edn. Cold Spring Harbor Laboratory Press, New York

Race B, Williams K, Orru CD, Hughson AG, Lubke L, Chesebro B (2018) Lack of transmission of chronic wasting disease to cynomolgus macaques. J Virol 92:e0550-18

Raeber AJ, Muramoto T, Kornberg TB, Prusiner SB (1995) Expression and targeting of Syrian hamster prion protein induced by heat shock in transgenic Drosophila melanogaster. Mech Dev 51:317-327

Repnikova E, Koles K, Nakamura M, Pitts J, Li H, Ambavane A, Zoran MJ, Panin VM (2010) Sialyltransferase regulates nervous system function in Drosophila. J Neurosci 30:6466-6476

Rivera-Milla E, Oidtmann B, Panagiotidis CH, Baier M, Sklaviadis T, Hoffmann R, Zhou Y, Solis GP, Stuermer CA, Malaga-Trillo E (2006) Disparate evolution of prion protein domains and the distinct origin of Doppel- and prion-related loci revealed by fishto-mammal comparisons. FASEB J 20:317-319 
Robinson SW, Nugent ML, Dinsdale D, Steinert JR (2014) Prion protein facilitates synaptic vesicle release by enhancing release probability. Hum Mol Genet 23:4581-4596

Roffe M, Beraldo FH, Bester R, Nunziante M, Bach C, Mancini G, Gilch S, Vorberg I, Castilho BA, Martins VR et al (2010) Prion protein interaction with stress-inducible protein 1 enhances neuronal protein synthesis via mTOR. Proc Natl Acad Sci U S A 107:13147-13152

Ron D (2002) Translational control in the endoplasmic reticulum stress response. J Clin Invest 110:1383-1388

Rosen DR, Martin-Morris L, Luo LQ, White K (1989) A Drosophila gene encoding a protein resembling the human beta-amyloid protein precursor. Proc Natl Acad Sci U S A 86:2478-2482

Saborio GP, Permanne B, Soto C (2001) Sensitive detection of pathological prion protein by cyclic amplification of protein misfolding. Nature 411:810-813

Safar J, Wille H, Itri V, Groth D, Serban H, Torchia M, Cohen FE, Prusiner SB (1998) Eight prion strains have $\operatorname{PrP}(\mathrm{Sc})$ molecules with different conformations. Nat Med 4:1157-1165

Salamat MKF, Blanco ARA, McCutcheon S, Tan KBC, Stewart P, Brown H, Smith A, de Wolf C, Groschup MH, Becher D et al (2021) Preclinical transmission of prions by blood transfusion is influenced by donor genotype and route of infection. PLoS Pathog 17:e1009276

Sanchez-Garcia J, Arbelaez D, Jensen K, Rincon-Limas DE, FernandezFunez P (2013) Polar substitutions in helix 3 of the prion protein produce transmembrane isoforms that disturb vesicle trafficking. Hum Mol Genet 22:4253-4266

Sanchez-Garcia J, Jensen K, Zhang Y, Rincon-Limas DE, FernandezFunez P (2016) A single amino acid (Asp159) from the dog prion protein suppresses the toxicity of the mouse prion protein in Drosophila. Neurobiol Dis 95:204-209

Schaller O, Fatzer R, Stack M, Clark J, Cooley W, Biffiger K, Egli S, Doherr M, Vandevelde M, Heim D et al (1999) Validation of a western immunoblotting procedure for bovine $\operatorname{PrP}(\mathrm{Sc})$ detection and its use as a rapid surveillance method for the diagnosis of bovine spongiform encephalopathy (BSE). Acta Neuropathol 98:437-443

Scheckel C, Imeri M, Schwarz P, Aguzzi A (2020) Ribosomal profiling during prion disease uncovers progressive translational derangement in glia but not in neurons. Elife 9:e62911

Siskova Z, Mahad DJ, Pudney C, Campbell G, Cadogan M, Asuni A, O'Connor V, Perry VH (2010) Morphological and functional abnormalities in mitochondria associated with synaptic degeneration in prion disease. Am J Pathol 177:1411-1421

Sorce S, Nuvolone M, Russo G, Chincisan A, Heinzer D, Avar M, Pfammatter M, Schwarz P, Delic M, Muller M et al (2020) Genome-wide transcriptomics identifies an early preclinical signature of prion infection. PLoS Pathog 16:e1008653

Stamp JT (1962) Scrapie: a transmissible disease of sheep. Vet Rec 74:357-362

Stamp JT, Brotherston JG, Zlotnik I, Mackay JM, Smith W (1959) Further studies on scrapie. J Comp Pathol 69:268-280

Supattapone S (2014) Elucidating the role of cofactors in mammalian prion propagation. Prion 8:100-105

Thackray AM, Andreoletti O, Bujdoso R (2016) Bioassay of prioninfected blood plasma in PrP transgenic Drosophila. Biochem J 473:4399-4412

Thackray AM, Andreoletti O, Bujdoso R (2018) Mammalian prion propagation in PrP transgenic Drosophila. Brain 141:2700-2710
Thackray AM, Andreoletti O, Spiropoulos J, Bujdoso R (2021) A new model for sensitive detection of zoonotic prions by PrP transgenic Drosophila. J Biol Chem 297:100878

Thackray AM, Di Y, Zhang C, Wolf H, Pradl L, Vorberg I, Andreoletti O, Bujdoso R (2014a) Prion-induced and spontaneous formation of transmissible toxicity in PrP transgenic Drosophila. Biochemical Journal 463:31-40

Thackray AM, Hopkins L, Bujdoso R (2007) Proteinase K-sensitive disease-associated ovine prion protein revealed by conformationdependent immunoassay. Biochem J 401:475-483

Thackray AM, Hopkins L, Lockey R, Spiropoulos J, Bujdoso R (2011) Emergence of multiple prion strains from single isolates of ovine scrapie. J Gen Virol 92:1482-1491

Thackray AM, Hopkins L, Lockey R, Spiropoulos J, Bujdoso R (2012a) Propagation of ovine prions from "poor" transmitter scrapie isolates in ovine PrP transgenic mice. Exp Mol Pathol 92:167-174

Thackray AM, Hopkins L, Spiropoulos J, Bujdoso R (2008) Molecular and transmission characteristics of primary-passaged ovine scrapie isolates in conventional and ovine PrP transgenic mice. J Virol 82:11197-11207

Thackray AM, Lam B, Shahira Binti Ab Razak A, Yeo G, Bujdoso R (2020) Transcriptional signature of prion-induced neurotoxicity in a Drosophila model of transmissible mammalian prion disease. Biochem J 477:833-852

Thackray AM, Muhammad F, Zhang C, Di Y, Jahn TR, Landgraf M, Crowther DC, Evers JF, Bujdoso R (2012b) Ovine PrP transgenic Drosophila show reduced locomotor activity and decreased survival. Biochem J 444:487-495

Thackray AM, Zhang C, Arndt T, Bujdoso R (2014b) Cytosolic PrP can participate in prion-mediated toxicity. J Virol 88:8129-8138

Tsuda L, Inoue YH, Yoo MA, Mizuno M, Hata M, Lim YM, AdachiYamada T, Ryo H, Masamune Y, Nishida Y (1993) A protein kinase similar to MAP kinase activator acts downstream of the raf kinase in Drosophila. Cell 72:407-414

van Keulen LJ, Bossers A, van Zijderveld F (2008) TSE pathogenesis in cattle and sheep. Vet Res 39:24

Vilotte JL, Soulier S, Essalmani R, Stinnakre MG, Vaiman D, Lepourry L, Da Silva JC, Besnard N, Dawson M, Buschmann A et al (2001) Markedly increased susceptibility to natural sheep scrapie of transgenic mice expressing ovine prp. J Virol 75:5977-5984

Vincenti JE, Murphy L, Grabert K, McColl BW, Cancellotti E, Freeman TC, Manson JC (2015) Defining the microglia response during the time course of chronic neurodegeneration. J Virol 90:3003-3017

Wang F, Wang X, Yuan CG, Ma J (2010) Generating a prion with bacterially expressed recombinant prion protein. Science 327:1132-1135

Wilham JM, Orru CD, Bessen RA, Atarashi R, Sano K, Race B, Meade-White KD, Taubner LM, Timmes A, Caughey B (2010) Rapid end-point quantitation of prion seeding activity with sensitivity comparable to bioassays. PLoS Pathog 6:e1001217

Wittmann CW, Wszolek MF, Shulman JM, Salvaterra PM, Lewis J, Hutton M, Feany MB (2001) Tauopathy in Drosophila: neurodegeneration without neurofibrillary tangles. Science 293:711-714

Publisher's Note Springer Nature remains neutral with regard to jurisdictional claims in published maps and institutional affiliations. 